\title{
Quantitative CT assessment of bronchial and vascular alterations in severe precapillary pulmonary hypertension
}

This article was published in the following Dove Medical Press journal: International Journal of COPD

\author{
Florence Coste $\mathrm{e}^{1,2, *}$ \\ Ilyes Benlala ${ }^{1,2, *}$ \\ Gaël Dournes ${ }^{1-3}$ \\ Claire Dromer 3 \\ Elodie Blanchard ${ }^{3}$ \\ Pierre-Olivier Girodet ${ }^{1-3}$ \\ Michel Montaudon ${ }^{1-3}$ \\ Fabien Baldacci ${ }^{4}$ \\ François Picard ${ }^{3}$ \\ Roger Marthan ${ }^{1-3}$ \\ François Laurent ${ }^{1-3, *}$ \\ Patrick Berger ${ }^{1-3, *}$ \\ 'Université de Bordeaux, Centre \\ de Recherche Cardio-Thoracique \\ de Bordeaux, U1045, F-33000 \\ Bordeaux, France; ${ }^{2}$ Centre de \\ Recherche Cardio-Thoracique de \\ Bordeaux, INSERM, U I 045, Université \\ de Bordeaux, CICI40I, F-33000 \\ Bordeaux, France; ${ }^{3} \mathrm{CHU}$ de Bordeaux, \\ Service d'Imagerie Thoracique et \\ Cardiovasculaire, Service des Maladies \\ Respiratoires, Service de Cardiologie, \\ CICI40I, Service d'Explorations \\ Fonctionnelles Respiratoires, F-33600 \\ Pessac, France; ${ }^{4}$ Université de \\ Bordeaux, LaBRI, F-33405 Talence \\ Cedex, France \\ *These authors contributed equally \\ to this work
}

Correspondence: Florence Coste Centre de Recherche Cardio-Thoracique de Bordeaux, INSERM, UI045, Université de Bordeaux, 146 Rue Léo Saignat, 33076 Bordeaux Cedex, France Tel +3354730275l Fax +33557571695

Email florence-coste@hotmail.fr
Background: Little is known about in vivo alterations at bronchial and vascular levels in severe pulmonary hypertension $(\mathrm{PH})$ of different etiologies. We aimed to compare quantitative computed tomography (CT) data from the following three groups of severe precapillary $\mathrm{PH}$ patients: COPD, idiopathic pulmonary arterial hypertension (iPAH), and chronic thromboembolic PH (CTEPH).

Patients and methods: This study was approved by the institutional review board. Severe PH patients (mean pulmonary arterial pressure $[\mathrm{mPAP}] \geq 35 \mathrm{mmHg}$ ) with COPD, iPAH, or CTEPH ( $n=24,16$, or 16, respectively) were included retrospectively between January 2008 and January 2017. Univariate analysis of mPAP was performed in each severe PH group. Bronchial wall thickness (WT) and percentage of cross sectional area of pulmonary vessels less than $5 \mathrm{~mm}^{2}$ normalized by lung area $\left(\% \mathrm{CSA}_{<5}\right)$ were measured and compared using $\mathrm{CT}$, and then combined to arterial partial pressure of oxygen $\left(\mathrm{PaO}_{2}\right)$ to generate a "paw score" compared within the three groups using Kruskal-Wallis and its sensitivity using Fisher's exact test.

Results: WT was higher and $\% \mathrm{CSA}_{<5}$ was lower in the COPD group compared to $\mathrm{PAH}$ and CTEPH groups. Mosaic pattern was higher in CTEPH group than in others. In severe PH patients secondary to COPD, mPAP was positively correlated to $\% \mathrm{CSA}_{<5}$. By contrast, in severe iPAH, this correlation was negative, or not correlated in severe CTEPH groups. In the COPD group, "paw score" showed higher sensitivity than in the other two groups.

Conclusion: Unlike in severe iPAH and CTEPH, severe PH with COPD can be predicted by "paw score" reflecting bronchial and vascular morphological differential alterations.

Keywords: computed tomography, pulmonary hypertension, COPD, prediction, quantitative

\section{Plain language summary}

Mortality of pulmonary hypertension (PH) increases with severity of the disease. It is thus crucial to identify severe forms of PH, characterized by a higher elevation of mPAP. In addition, little is known about bronchial and vascular alterations in severe $\mathrm{PH}$ of different etiologies.

Our purpose was to compare the following three groups of severe precapillary PH patients using quantitative computed tomography (CT): COPD, idiopathic pulmonary arterial hypertension (iPAH) and chronic thromboembolic PH (CTEPH).

Bronchial wall thickness (WT) was higher and small pulmonary vessels area was lower in the COPD group compared to iPAH and CTEPH groups. The mPAP was positively correlated to small pulmonary vessels area in the COPD group and negatively or not correlated in $\mathrm{PAH}$ or CTEPH groups.

Unlike severe iPAH or CTEPH, severe PH secondary to COPD is characterized by vascular and bronchial morphological alterations assessed by quantitative CT. These values combined with that of $\mathrm{PaO}_{2}$ in a "paw score" can predict the presence of severe $\mathrm{PH}$, only in COPD patients. 
Such a paw score could be thus used to select COPD patients for right heart catheterization.

\section{Introduction}

Pulmonary hypertension $(\mathrm{PH})$ is defined by a mean pulmonary arterial pressure $(\mathrm{mPAP}) \geq 25 \mathrm{mmHg}$, at rest, subsequently inducing right heart failure, and ultimately patient's death. ${ }^{1,2}$ Among the five groups of $\mathrm{PH}$, defined in the last international classification, ${ }^{1}$ three of them correspond to a precapillary $\mathrm{PH}$ (ie, $\mathrm{PH}$ due to lung diseases and/or hypoxemia [group 3], pulmonary arterial hypertension [(PAH), group 1] notably idiopathic PAH (iPAH), and chronic thromboembolic PH [(CTEPH), group 4)]. Despite comparable hemodynamic alterations assessed invasively by right heart catheterization (RHC), these three groups have different underlying mechanisms, treatment, and prognosis. ${ }^{1}$

The mortality of $\mathrm{PH}$ increases by more than fourfold when the mPAP increases by $10 \mathrm{mmHg}{ }^{3}$ It is thus crucial to identify severe forms of $\mathrm{PH}$, characterized by a higher elevation of mPAP. ${ }^{4}$ In patients with COPD (group 3), severe $\mathrm{PH}$ is defined as $\mathrm{mPAP} \geq 35 \mathrm{mmHg}$ at rest. ${ }^{5}$ However, RHC cannot be performed in all COPD patients. To circumvent this limitation, a "paw score" was proposed, combining arterial partial pressure of oxygen $\left(\mathrm{PaO}_{2}\right)$ and quantitative computed tomography $(\mathrm{CT})$ measurements of both bronchial wall thickness (WT) and small pulmonary vessels. This "paw score" was able to predict the presence of severe $\mathrm{PH}$ in a COPD population with $75 \%$ sensitivity and $80 \%$ specificity. ${ }^{6}$ Interestingly, its negative predictive value was more than $95 \%$, allowing to predict the absence of severe $\mathrm{PH}$ when the "paw score" was $<5$ with $<5 \%$ error. ${ }^{6}$ Although the "paw score" appeared accurate in a COPD population, it remains unclear whether this score may be relevant to other forms of severe PH. Moreover, relationships between mPAP and quantitative CT measurements of both bronchi and small pulmonary vessels have not been described so far in the various groups of patients with severe precapillary $\mathrm{PH}$.

Thus, we aimed at comparing quantitative CT measurements of bronchial wall, lung parenchyma, and small pulmonary vessels in patients with severe precapillary $\mathrm{PH}$ related to COPD, iPAH, or CTEPH. We also assessed correlations between mPAP, CT, clinical, and functional parameters in order to find predictors of mPAP variability. Finally, we compared the sensitivity of the "paw score" to diagnose severe $\mathrm{PH}$ in each of these three groups.

\section{Patients and methods} Study population

This study was observational, retrospective, and conducted according to the principles of the Declaration of Helsinki and approved by our institutional review board. One hundred eighty-nine patients were consecutively referred for complete examination of severe $\mathrm{PH}$ to our institution, a tertiary medical center, between January 2008 and January 2017. From a prior study, ${ }^{6} 20$ COPD patients were also included in the current study (out of 24 patients) and none in the two other groups. However, these 20 patients were completely reanalyzed by another radiologist and they were implemented with four new subjects. Before initiation of any treatment, within 1 week, all patients had physical examination, medical questioning, 6-minute walk tests (6-MWT), blood tests (C-reactive protein [CRP], brain natriuretic peptide, and HIV serology), transthoracic-echocardiography, ventilation/ perfusion scintigraphy, pulmonary function test (PFT), RHC, and unenhanced CT within a minimal period of 1 month of disease stability. PFT involved body plethysmography, transfer lung capacity of carbon monoxide ([TLCO]; Medisoft, Sorinnes, Belgium), and arterial blood gases. Reference values were chosen from the European Respiratory Society and the American Thoracic Society guidelines. ${ }^{7,8}$ From the 189 screened patients, 103 patients had both mPAP value $\geq 35 \mathrm{mmHg}$ at $\mathrm{RHC}^{5}$ and a diagnosis of either COPD, iPAH, or CTEPH. However, 16 patients were not fully screened and 19 patients could not be included because of associated diseases (Figure 1). Thus, from the 68 remaining patients, we focused the study on the 56 adult patients with only severe precapillary $\mathrm{PH}$ with either COPD, iPAH, or CTEPH, without any other condition to explain $\mathrm{PH}$, and with an adequate $\mathrm{CT}$ examination without any abnormality possibly altering CT measurements (Figure 1). Chest CT scans were acquired at full inspiration on a Somatom Definition 64 (Siemens, Munich, Germany). Dedicated and validated software were used to quantitatively analyze scans..$^{9,10}$ Emphysema was automatically quantified with Myrian software (Intrasense, Montpellier, France) using the low-attenuation area percent (LAA\%). ${ }^{6,11}$ Mosaic attenuation was assessed using a semiquantitative score derived from evaluation of each lobe. ${ }^{12}$ Bronchial wall area (WA), lumen area, and WT were automatically quantified on orthogonal bronchial cross sections using previously validated homemade software (ie, Neko). ${ }^{10,13}$ Small vessel areas from CT images were automatically measured, as previously described..$^{6,14-18}$ Percentage of cross sectional area of pulmonary vessels less than $5 \mathrm{~mm}^{2}$ normalized by lung area $\left(\% \mathrm{CSA}_{<5}\right)$ at each CT slice were acquired using ImageJ software. Large vessel diameters were manually measured, at the level of pulmonary artery bifurcation, for both pulmonary arterial truncus (AP) and ascending aorta (AO) using the same axial image. ${ }^{6,11}$ 


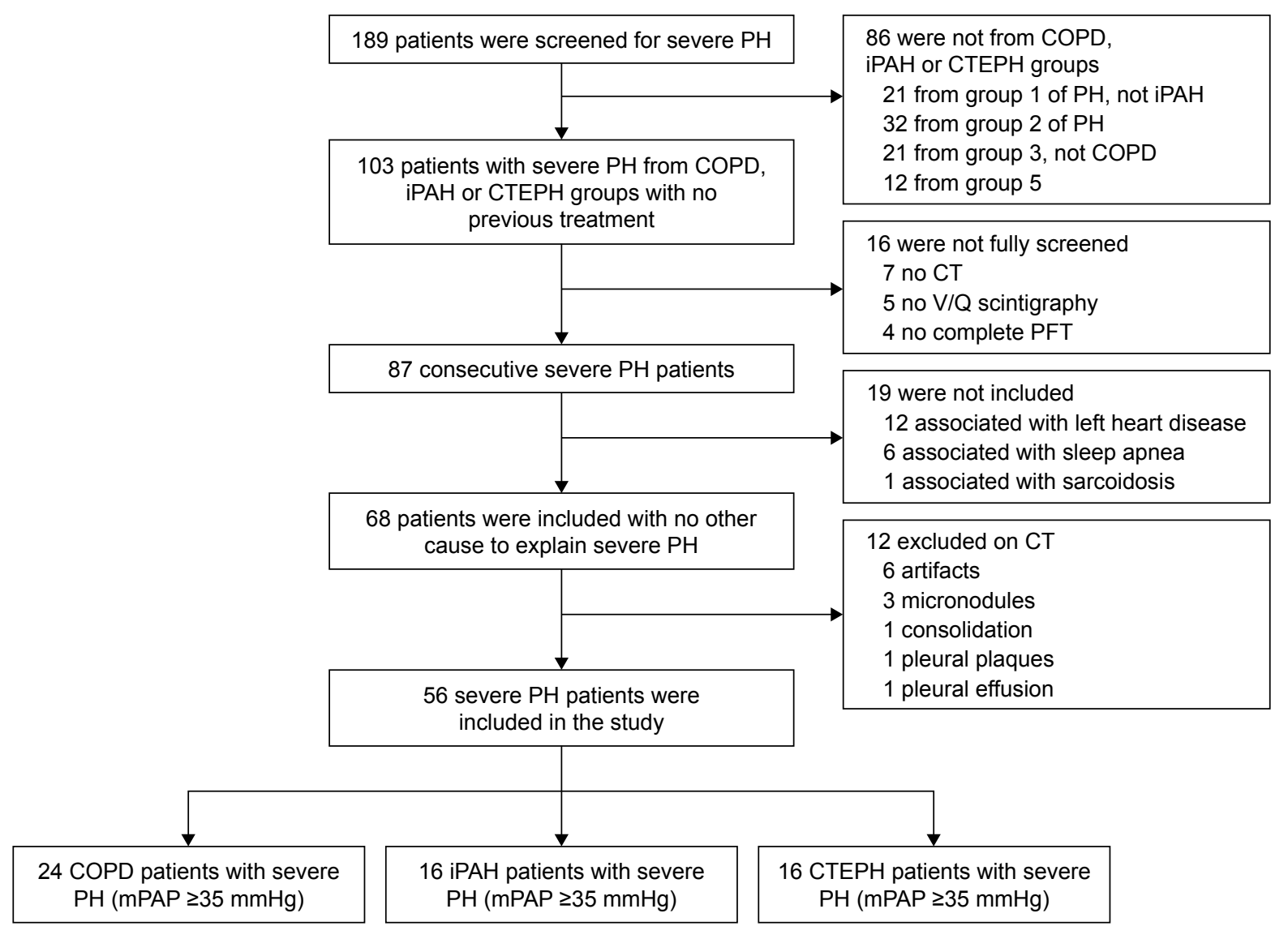

Figure I Flowchart of study design.

Note: Number of patients who were screened, enrolled, and assigned to a study group.

Abbreviations: CT, computed tomography; CTEPH, chronic thromboembolic PH; iPAH, idiopathic pulmonary arterial hypertension; mPAP, mean pulmonary arterial pressure; PFT, pulmonary function tests; $\mathrm{PH}$, pulmonary hypertension; V/Q, ventilation/perfusion scintigraphy.

\section{Statistical analyses}

Statistical analyses were performed using NCSS software (v. 2001; NCSS, Kaysville, UT, USA). Results are expressed as mean with SD and analyzed using one-way ANOVA and Tukey post hoc tests. Parameters that were not normally distributed are expressed as median with interquartile ranges and tested by Kruskal-Wallis and multiple comparisons z-value post hoc tests. Categorical variables were analyzed with Fisher's exact tests. Univariate correlations were assessed using Pearson's correlation coefficient test. In order to predict severe PH, "paw scores" were built, combining three variables, ie, $\mathrm{PaO}_{2}$, WT, and $\% \mathrm{CSA}_{<5}$, as described elsewhere (Table S1). ${ }^{6} P$-value $<0.05$ was considered significant.

Details about PFT, RHC, CT protocols, echocardiography, "paw score", and statistical analysis, are available in the electronic supplementary material.

\section{Ethics approval and informed consent}

This study was observational, retrospective, and conducted according to the principles of the Declaration of Helsinki and approved by our institutional review board "the Ethics
Committee of the University Hospital of Bordeaux" reference: GP-CE 2018/20. Every patient was informed and agreed that their data can be used for further research studies anonymously. Data were anonymized and they complied with the requirements of the "Commission nationale informatique et libertés" (CNIL) that approved the methods this organization was being responsible for ensuring the ethical use of data collected for scientific purposes in France (approval number: 1909530 v 0).

\section{Results}

\section{Patients characteristics}

Among the 56 included patients with severe PH, 24 patients suffered from COPD, 16 from $\mathrm{PAH}$, and 16 from CTEPH (Figure 1). Demographic, plethysmographic, clinical, biological, and hemodynamic characteristics of the three groups are detailed in Table 1. Significant lower $\mathrm{FEV}_{1}, \mathrm{FEV}_{1} /$ FVC ratio, and TLCO, and a higher residual volume were found in COPD subjects compared to the other two groups. Moreover, both a lower $\mathrm{PaO}_{2}$ and a higher left ventricular ejection fraction were measured in COPD patients compared 
Table I Characteristics of severe $\mathrm{PH}$ patients

\begin{tabular}{|c|c|c|c|c|}
\hline & COPD with severe PH & Severe iPAH & Severe CTEPH & $P$-value \\
\hline $\mathrm{N}$ & 24 & 16 & 16 & \\
\hline \multicolumn{5}{|l|}{ Age } \\
\hline Years & $70(64-73)$ & $71(62-76)$ & $66(56-75)$ & 0.59 \\
\hline \multicolumn{5}{|l|}{ Sex ratio } \\
\hline Male/female & $20 / 4^{\mathrm{a}, \mathrm{b}}$ & $9 / 7^{c}$ & $5 / 1 I^{c}$ & $<0.01$ \\
\hline \multicolumn{5}{|l|}{ BMI } \\
\hline $\mathrm{kg} \cdot \mathrm{m}^{-2}$ & $26 \pm 5$ & $25 \pm 4$ & $25 \pm 7$ & 0.67 \\
\hline \multicolumn{5}{|l|}{ PFT } \\
\hline $\mathrm{FEV}_{1}(\%$ pred) & $55 \pm 2^{a, b}$ & $91 \pm 14^{c}$ & $92 \pm 14^{c}$ & $<0.01$ \\
\hline $\mathrm{FEV}_{1} / \mathrm{FVC}(\%)$ & $57(49-63)^{\mathrm{a}, \mathrm{b}}$ & $73(72-78)^{c}$ & $76(74-78)^{c}$ & $<0.01$ \\
\hline FVC (\%) & $80 \pm 22^{\mathrm{a}, \mathrm{b}}$ & $98 \pm 17^{c}$ & $97 \pm 14^{c}$ & $<0.01$ \\
\hline TLC (\%) & $95(87-104)$ & $93(83-101)$ & $99(93-101)$ & 0.26 \\
\hline $\mathrm{RV}(\%)$ & $115(|0|-|4|)^{\mathrm{a}}$ & $92(83-105)^{c}$ & $109(87-115)$ & $<0.01$ \\
\hline TLCO (\%) & $23(16-32)^{a, b}$ & $40(35-80)^{c}$ & $66(57-87)^{c}$ & $<0.01$ \\
\hline \multicolumn{5}{|l|}{ 6-MWT } \\
\hline Distance (m) & $275(180-300)$ & $317(270-390)$ & $325(228-510)$ & 0.14 \\
\hline \multicolumn{5}{|l|}{ Arterial blood gases } \\
\hline $\mathrm{PaO}_{2}(\mathrm{mmHg})$ & $49(46-53)^{b}$ & $67(53-75)^{c}$ & $60(52-68)$ & $<0.01$ \\
\hline $\mathrm{PaCO}_{2}(\mathrm{mmHg})$ & $34(29-37)$ & $32(30-36)$ & $33(31-36)$ & 0.60 \\
\hline \multicolumn{5}{|l|}{ RHC } \\
\hline $\mathrm{mPAP}(\mathrm{mmHg})$ & $45 \pm 7$ & $42 \pm 4$ & $47 \pm 9$ & 0.11 \\
\hline sPAP $(\mathrm{mmHg})$ & $72 \pm 14^{b}$ & $69 \pm 11^{b}$ & $83 \pm 16^{a, c}$ & 0.01 \\
\hline $\mathrm{dPAP}(\mathrm{mmHg})$ & $29 \pm 6$ & $27 \pm 5$ & $27 \pm 8$ & 0.54 \\
\hline PCWP (mmHg) & $9 \pm 3$ & $8 \pm 3$ & $8 \pm 3$ & 0.55 \\
\hline Gradient (mmHg) & $20 \pm 5$ & $20 \pm 6$ & $18 \pm 8$ & 0.85 \\
\hline PVR (Wood unit) & $8 \pm 3$ & $9 \pm 4$ & $10 \pm 4$ & 0.19 \\
\hline PVRi (Wood unit.m-2) & $15 \pm 6$ & $17 \pm 4$ & $16 \pm 6$ & 0.51 \\
\hline CO $\left(\right.$ L.min min $\left.^{-1}\right)$ & $5 \pm 1.2$ & $4 \pm 1.4$ & $4 \pm 1.1$ & 0.09 \\
\hline $\mathrm{Cl}\left(\mathrm{L} \cdot \mathrm{min}^{-1} \cdot \mathrm{m}^{-2}\right)$ & $3 \pm 0.7$ & $2 \pm 0.7$ & $2 \pm 0.5$ & 0.14 \\
\hline \multicolumn{5}{|l|}{ Echocardiography } \\
\hline sPAP $(\mathrm{mmHg})$ & $69 \pm 24$ & $72 \pm 18$ & $82 \pm 24$ & 0.28 \\
\hline ITVmax (m/s) & $3.8 \pm 0.7$ & $3.8 \pm 0.4$ & $4.1 \pm 0.6$ & 0.26 \\
\hline ITGdmax (mmHg) & $59 \pm 22$ & $59 \pm 13$ & $69 \pm 21$ & 0.28 \\
\hline LVEF (\%) & $68 \pm 9^{a}$ & $57 \pm 10^{c}$ & $64 \pm 11$ & 0.02 \\
\hline \multicolumn{5}{|l|}{ Biology } \\
\hline CRP $(\mathrm{pg} / \mathrm{mL})$ & $4(2-7)$ & $6(4-16)$ & $5(I-6)$ & 0.27 \\
\hline BNP (mg/mL) & $375(35-610)$ & $467(66-936)$ & $186(73-376)$ & 0.29 \\
\hline
\end{tabular}

Notes: Data are mean $\pm S D$ for continuous normal variables, or median with IQR if their distribution was not normal. Comparisons of parametric and nonparametric variables were performed using ANOVA and with Kruskal-Wallis tests, respectively. ${ }^{a}$ Different from iPAH group, bdifferent from CTEPH group, and 'different from COPD group. Abbreviations: BMI, body mass index; BNP, brain natriuretic peptide; Cl, cardiac index; $\mathrm{CO}$, cardiac output; CRP, C-reactive protein; CTEPH, chronic thromboembolic PH; FVC, forced volume capacity; Gradient, dPAP-PCWP; iPAH, idiopathic pulmonary arterial hypertension; ITGdmax, maximal transtricuspid pressure gradient; ITVmax, maximal tricuspid regurgitation velocity; IQR, interquartile range; LVEF, left ventricular ejection fraction; 6-MWT, 6-minute walk test; $m$, s, dPAP, mean, systolic, diastolic pulmonary arterial pressure; PCWP, pulmonary capillary wedge pressure; PFT, pulmonary function test; PH, pulmonary hypertension; PVR, pulmonary vascular resistance; $\mathrm{PVRi}$, indexed PVR; $\mathrm{PaCO}_{2}$, arterial partial pressure of carbon dioxide; $\mathrm{PaO}_{2}$, arterial partial pressure of oxygen; pred, predicted; $\mathrm{RHC}$, right heart catheterization; $\mathrm{RV}$, residual volume; TLC, total lung capacity; TLCO, transfer lung capacity of carbon monoxide. 
to iPAH patients (Table 1). The mPAP was similar in the three groups, as well as most of the RHC parameters except the systolic PAP (sPAP), which was higher in severe CTEPH patients (Table 1).

\section{Comparison of CT measurements of bronchi, parenchyma, and vessels}

Morphological CT parameters were compared in the three groups (Table 2). Bronchial morphological parameters were greater in COPD patients with severe PH ( in iPAH (ie, WT and WA; Figure S2) and CTEPH (ie, WT; Figure S3). Moreover, emphysema extent, assessed by the $\mathrm{LAA} \%$, was higher in patients with COPD than in those with iPAH or CTEPH. In addition, mosaic attenuation score was higher in patients with severe CTEPH than in those with iPAH or COPD. Whereas large vessels ratio was not different within the three groups, the $\% \mathrm{CSA}_{<5}$ was smaller in patients with COPD than in those with iPAH.

\section{Univariate analysis of mPAP}

In COPD patients with severe $\mathrm{PH}$, significant univariate correlations were found between MPAP and a variety of variables including: CRP, echocardiographic sPAP, $\% \mathrm{CSA}_{<5}$, and WT (Tables 3 and $\underline{\mathrm{S} 2}$ ). In severe iPAH patients, mPAP was correlated only with maximal tricuspid regurgitation velocity (ITVmax) and $\% \mathrm{CSA}_{<5}$. Correlation between mPAP and $\% \mathrm{CSA}_{<5}$ was positive in patients with COPD, whereas it was negative in those with $\mathrm{iPAH}$ (Figure S4). By contrast, mPAP of severe CTEPH patients was not correlated to $\% \mathrm{CSA}_{<5}$, but with $\mathrm{LAA} \%$, TLCO, and 6-MWT.

\section{Validity of "paw scores" in each group and comparison to sPAP on echocardiography}

As a consequence, the "paw score" combining three variables, ie, $\mathrm{PaO}_{2}$, WT, and \% $\mathrm{CSA}_{<5}$, was significantly higher in COPD patients with severe $\mathrm{PH}$ than in the two other groups, without any difference between severe iPAH and severe CTEPH (Figure 2A). Using a threshold of 5, as assessed previously, ${ }^{6}$ the sensitivity of "paw score" for predicting the presence of severe $\mathrm{PH}$ was $87.5 \%(21 / 24), 43.8 \%$ (7/16), and $62.5 \%(10 / 16)$ in COPD, iPAH, and CTEPH groups, respectively. A significant difference in the number of true positives and false negatives between the three groups of severe $\mathrm{PH}$ was found (Figure 2B). We also assessed the sensitivity of ultrasound echocardiography to predict the presence of severe PH using various sPAP cutoff (ie, $50 \mathrm{mmHg},{ }^{19} 60 \mathrm{mmHg},{ }^{20}$ and $65 \mathrm{mmHg}^{21}$ in the three groups of patients (Table S3 ). In COPD patients, the sensitivity of the "paw score" was higher than that of echocardiography for each cutoff.

\section{Discussion}

The present study demonstrates that, unlike severe iPAH or severe CTEPH, severe PH secondary to COPD is characterized by vascular and bronchial morphological alterations assessed by quantitative CT. Values derived from these measurements, combined with that of $\mathrm{PaO}_{2}$ in

Table 2 Comparison of CT parameters between groups

\begin{tabular}{|c|c|c|c|c|}
\hline & COPD with severe PH & Severe iPAH & Severe CTEPH & $P$-value \\
\hline $\mathrm{n}$ & 24 & 16 & 16 & \\
\hline \multicolumn{5}{|l|}{ Bronchi } \\
\hline WA & $20.06 \pm 4.63^{a}$ & $16.44 \pm 3.25^{\mathrm{b}}$ & $17.61 \pm 3.76$ & 0.02 \\
\hline LA & $9.03 \pm 2.73$ & $8.20 \pm 2.49$ & $9.28 \pm 2.84$ & 0.50 \\
\hline WT & $1.34 \pm 0.15^{\mathrm{a}, \mathrm{c}}$ & $1.19 \pm 0.15^{b}$ & $1.20 \pm 0.13^{\mathrm{b}}$ & $<0.01$ \\
\hline \multicolumn{5}{|l|}{ Parenchyma } \\
\hline LAA $\%$ & $4.59(2.70-10.50)^{a, c}$ & $1.26(0.74-1.84)^{b}$ & $1.30(0.84-2.80)^{\mathrm{b}}$ & $<0.01$ \\
\hline Mosaic attenuation & $0(0-0)^{c}$ & $0(0-17)^{c}$ & $30(4-52)^{\mathrm{a}, \mathrm{b}}$ & $<0.01$ \\
\hline \multicolumn{5}{|l|}{ Vessels } \\
\hline AP/AO & $1.06(0.98-1.16)$ & $1.09(0.99-1.16)$ & $1.14(1.08-1.21)$ & 0.11 \\
\hline$\% \mathrm{CSA}_{<5}$ & $0.54 \pm 0.19^{a}$ & $0.77 \pm 0.29^{b}$ & $0.67 \pm 0.24$ & 0.01 \\
\hline
\end{tabular}

Notes: Data are mean \pm SD for continuous normal variables, or median with IQR if their distribution is not normal. Comparisons of parametric and nonparametric variables were performed using ANOVA and with Kruskal-Wallis tests, respectively. ${ }^{\mathrm{a} D i f f e r e n t}$ from iPAH group, ${ }^{\mathrm{b}}$ different from COPD group, and ${ }^{\mathrm{c}} \mathrm{different}$ from CTEPH group.

Abbreviations: AO, aorta; AP, pulmonary arterial truncus; \%CSA ${ }_{<5}$, percentage of cross sectional area of pulmonary vessels less than 5 mm ${ }^{2}$ normalized by lung area; CTEPH, chronic thromboembolic PH; iPAH, idiopathic pulmonary arterial hypertension; IQR, interquartile range; LA, mean lumen area (mm²); LAA\%, low-attenuation area percentage; $\mathrm{PH}$, pulmonary hypertension; WA, mean wall area $\left(\mathrm{mm}^{2}\right)$; WT, mean wall thickness $(\mathrm{mm})$. 
Table 3 Univariate correlations between mPAP and CT parameters

\begin{tabular}{|c|c|c|c|c|c|c|c|c|c|c|}
\hline & & \multicolumn{3}{|c|}{ COPD with severe PH } & \multicolumn{3}{|c|}{ Severe iPAH } & \multicolumn{3}{|c|}{ Severe CTEPH } \\
\hline & & $\mathbf{n}$ & Coef & $P$-value & $\mathbf{N}$ & Coef & $P$-value & $\mathbf{n}$ & Coef & $P$-value \\
\hline Parenchyma emphysema & LAA\% & 24 & -0.10 & 0.65 & 16 & 0.45 & 0.08 & 16 & -0.58 & 0.02 \\
\hline Mosaic attenuation & MA\% & 24 & 0 & I & 16 & 0.08 & 0.77 & 16 & 0.44 & 0.08 \\
\hline \multirow[t]{3}{*}{ Bronchi } & WA & 24 & 0.38 & 0.07 & 16 & -0.04 & 0.88 & 16 & 0.06 & 0.81 \\
\hline & LA & 24 & 0.15 & 0.49 & 16 & 0.13 & 0.63 & 16 & -0.02 & 0.93 \\
\hline & WT & 24 & 0.43 & 0.04 & 16 & -0.15 & 0.59 & 16 & 0.13 & 0.62 \\
\hline \multicolumn{11}{|l|}{ Vessels } \\
\hline Large vessels & AP/AO & 24 & 0.01 & 0.95 & 16 & 0.45 & 0.08 & 16 & 0.38 & 0.15 \\
\hline Small vessels & $\% \mathrm{CSA}_{<5}$ & 24 & 0.41 & 0.04 & 16 & -0.55 & 0.03 & 16 & 0.14 & 0.61 \\
\hline
\end{tabular}

Notes: Data are Pearson correlation coefficients. Bold indicates statistical significance, $P<0.05$.

Abbreviations: AO, aorta; AP, pulmonary arterial truncus diameter; $\% \mathrm{CSA}_{<5}$, percentage of cross sectional area of pulmonary vessels less than 5 mm ${ }^{2}$ normalized by lung area; CTEPH, chronic thromboembolic PH; CT, computed tomography; Coef, coefficient; LA, mean lumen area (mm²); iPAH, idiopathic pulmonary arterial hypertension; LAA\%, low-attenuation area percentage; MA, mosaic attenuation; mPAP, mean pulmonary arterial pressure; PH, pulmonary hypertension; WA, mean wall area (mm²); WT, mean wall thickness $(\mathrm{mm})$.

a "paw score" can predict the presence of severe $\mathrm{PH}$, in COPD patients.

To the best of our knowledge, this quantitative CT study is the first one including cohorts from three distinct groups of precapillary severe $\mathrm{PH}$, and reporting in vivo data of small vessels alterations in severe $\mathrm{PH}$. Whereas these three groups presented similar values of $\mathrm{mPAP}$, all being $\geq 35 \mathrm{mmHg}$, several differences in quantitative CT parameters between groups and univariate relationships with MPAP within groups have been highlighted. These three groups of severe $\mathrm{PH}$ patients allows us to consider two groups as control for the third one. Regarding bronchial parameters, we showed that WT was higher in COPD patients with severe $\mathrm{PH}$, as compared to the two other groups and was positively correlated to mPAP only in COPD, as previously described in the literature, ${ }^{6,11}$ but not in the two other groups, a finding that has not been reported so far. Regarding vascular parameters, the $\% \mathrm{CSA}_{<5}$ was lower in COPD patients with severe
PH compared to iPAH. This result could be related with the emphysema extent, which was higher in COPD patients. In addition, a strong negative correlation between $\% \mathrm{CSA}_{<5}$ and emphysema has been demonstrated in this study confirming previous findings. ${ }^{15,17,18}$ Moreover, we demonstrated a positive correlation between mPAP and $\% \mathrm{CSA}_{<5}$ in COPD patients with severe $\mathrm{PH}$, in line with recent published results. ${ }^{6}$ By contrast, this correlation was negative in severe $\mathrm{PAH}$. Such a negative correlation between $\mathrm{mPAP}$ values and $\% \mathrm{CSA}_{<5}$ may suggest that the decrease in the number of vascular structure may accompany iPAH. This observation could be explained by angiogenesis disturbance in iPAH.,22 Our finding may bring insights into this uncertainty, suggesting that severe PH in COPD may be secondary to complex pathophysiology interactions that might be different from iPAH. These opposite findings cannot, nevertheless, rule out the previously proposed hypothesis that the severity of PH in COPD might be related with coexistence of iPAH. ${ }^{5,23,24}$ In the present study,
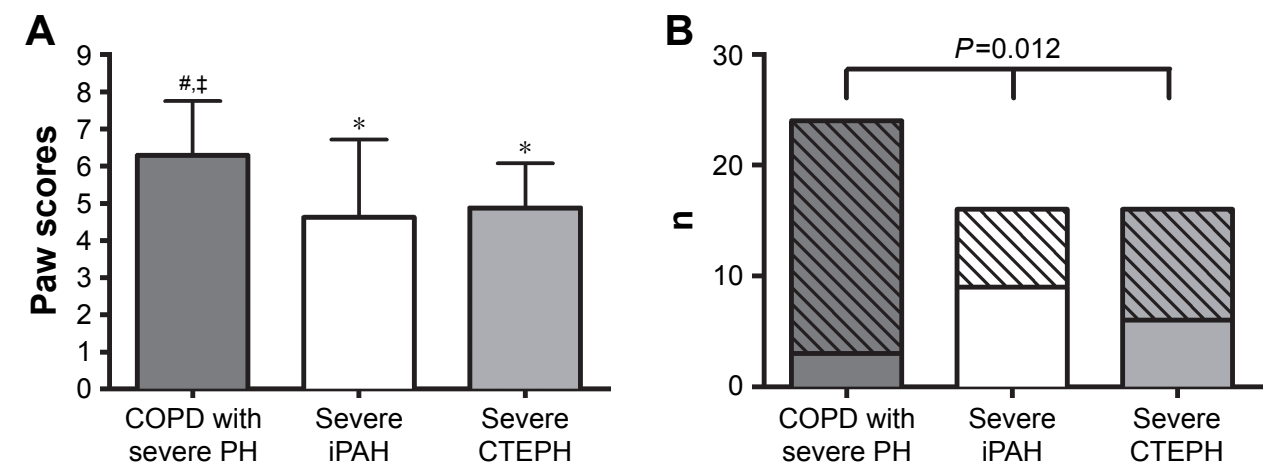

Figure 2 Comparison of "paw score" and its sensitivity between severe PH groups.

Notes: (A) Comparison of "paw scores" in each severe PH groups: COPD, iPAH, and CTEPH. Comparison was performed using Kruskal-Wallis and multiple comparisons z-value post hoc tests. *Different from COPD group, "Different from iPAH group, "Different from CTEPH group. (B) Comparison of "paw score" sensitivity in each severe $\mathrm{PH}$ group was assessed by a Fisher's exact test. Hashed bars represent true positives and plain bars represent false negatives.

Abbreviations: $\mathrm{CTEPH}$, chronic thromboembolic $\mathrm{PH}$; iPAH, idiopathic pulmonary arterial hypertension; $\mathrm{PH}$, pulmonary hypertension. 
there was also no correlation between $\% \mathrm{CSA}_{<5}$ and $\mathrm{mPAP}$ within the CTEPH population. This result is in agreement with that published by Rahaghi et al, ${ }^{25}$ who reported that the volume of small vessels with cross-sectional area $<5 \mathrm{~mm}^{2}$, assessed by a $3 \mathrm{D}$ reconstruction of the intraparenchymal pulmonary vasculature, was not correlated with mPAP, but with cardiac index.

With respect to PFT parameters, as expected, we found marked differences between COPD and the other groups. It should be noted that three severe iPAH patients presented a mild restrictive defect, assessed by a total lung capacity lower than $80 \%$ of predicted, as previously reported by others. ${ }^{26}$ Indeed, it has been hypothesized that, in iPAH, the mechanical coupling of vessels and airways with changes in vascular rigidity could lead to a reduction in lung compliance. ${ }^{26,27}$ Moreover, we did not observe any correlation between mPAP and PFT parameters in both COPD and iPAH groups, as already shown in previous studies. ${ }^{6,14,23,27}$ Regarding the relationship between PFT and mPAP in CTEPH, to the best of our knowledge, the lack of correlations between these parameters has not been reported before. However, we found a significant correlation between MPAP and TLCO in patients with severe CTEPH. Although hypoxia was believed to be a factor causing $\mathrm{PH},{ }^{1,28}$ in agreement with numerous studies, no significant correlation has been reported between $\mathrm{PaO}_{2}$ and mPAP within COPD group of severe $\mathrm{PH}^{6,23}$ and iPAH. ${ }^{29}$ In the present study, the significant difference shown between COPD and $\mathrm{PAH}$ groups is consistent with Chaouat et al's report, in which COPD patients with severe $\mathrm{PH}$ showed severe hypoxia whereas patients with severe iPAH had only mild hypoxia. ${ }^{6,23,29}$

Regarding quantitative CT parameters, there is a renewed interest in the identification and evaluation of COPD phenotypes, and pulmonary imaging biomarkers may contribute to determine these phenotypes. CT has several advantages in this field, being the most commonly used method for imaging the lung on one side, and, on the other side, being able to provide quantitative data related to alterations of components of the lung, ie, parenchyma, bronchi, and vascular compartments. In the particular setting of COPD, a close relationship between pulmonary arterial pressure and bronchial wall thickening has already been shown. ${ }^{11}$ Quantitative CT data derived from small vessels analysis have also suggested that a vascular alteration is more likely to explain severe $\mathrm{PH}$ in COPD rather than an airway disease. ${ }^{6,23}$ The role of both bronchial and small vessel alteration in the prediction of severe $\mathrm{PH}$ in COPD patients is supported by our univariate analysis. Using quantitative CT, a previous hypothesis that only tissue destruction and emphysema extent could lead to the increase of mPAP in COPD patients has already been disproved by recent studies. ${ }^{6,11,14}$ The present study confirms these results, since there was no correlation between mPAP and emphysema extent.

In this study, we found that a score combining $\mathrm{PaO}_{2}$ and both bronchial and vascular quantitative CT parameters, ie, the so-called "paw score" had a greater sensitivity for detecting severe PH in COPD patients. Interestingly, although the specificity of the "paw score" cannot be calculated, since true negatives and false positives were not available, its sensitivity was significantly higher in COPD than in $\mathrm{PPAH}$ and CTEPH groups, further supporting the interest of calculating the "paw score" in COPD patients only. These differences might be related to different morphological and functional alterations of bronchial and vascular components in other groups.

Other non-interventional study, ie, echocardiography, is currently used to explore PH. Indeed, in the present study, we observed that the sensitivity to detect severe PH in COPD group was higher with "paw score" than that with sPAP. Conversely, we showed that the sensitivity to detect severe PH with "paw score" was lower than that of sPAP, in iPAH or CTEPH patients. Indeed, ultrasound echocardiography is a very useful tool to detect PH. However, it suffers some limitation such as, insufficient tricuspid regurgitation prevents sPAP estimation, explaining some missing values, and in COPD patients hyperinflated lung can increase the difficulty of measurement. ${ }^{30}$ These observations might suggest that echocardiography should be preferred to detect severe $\mathrm{PH}$ in iPAH and CTEPH patients, whereas "paw score" should be preferred in COPD patients.

The present study suffers from some limitations. First, the study design was observational and retrospective. However, 1) all consecutive patients were characterized using the same processes during the whole inclusion period; 2) the definition of severe PH (ie, mPAP $\geq 35 \mathrm{mmHg}$ ) was the same for the three groups; and 3) CT scans have been acquired and analyzed consistently in the three groups. Second, since severe $\mathrm{PH}$ is uncommon, the number of patients in each group was limited. Third, considering small vessel measurements, veins cannot be distinguished from arteries using CT scan. The study, however, was limited to precapillary PH at RHC. Fourth, $\% \mathrm{CSA}_{<5}$ is a global measurement area, irrespective of wall and lumen changes in the vessel, thus making impossible the distinction between lumen narrowing and vessel wall thickening. Finally, a multivariate analysis has not been performed since it would have been underpowered by the low number of patient in each group. 


\section{Conclusion}

We demonstrated that the "paw score" (ie, combination of quantitative CT measurements of both bronchial thickness and vascular alterations with $\mathrm{PaO}_{2}$ ) can predict the presence of severe PH, in COPD patients only. Thus, the "paw score" is not appropriate to predict $\mathrm{PH}$ severity in iPAH or in CTEPH patients. Therefore, quantitative CT may be used to select among patients with COPD, who should be prioritized for RHC.

\section{Data availability}

The datasets used and/or analyzed during the current study are available from the corresponding author on reasonable request.

\section{Acknowledgments}

Berger reports grants from Laboratory of Excellence (LabEx) Transitional Research International Laboratory (TRAIL, Université de Bordeaux, France) ANR-10-LABX-57, during the conduct of the study. Laurent reports grants from TRAIL ANR-10-LABX-57, during the conduct of the study. Coste reports funding for salary from LabEx TRAIL ANR-10LABX-57, during the conduct of the study. This study has received funding from the LabEx TRAIL, ANR-10-LABX-57.

\section{Author contributions}

Conception and design: FC, GD, FL, PB; analysis and interpretation: FC, IB, GD, FL, PB; drafting the manuscript for important intellectual content: FC, IB, GD, FL, PB; revising the manuscript for important intellectual content: FC, IB, GD, RM, FL, PB; and final approval of the manuscript: FC, IB, GD, CD, EB, POG, MM, FB, FP, RM, FL, PB. All authors contributed to data analysis, drafting and revising the article, gave final approval of the version to be published, and agree to be accountable for all aspects of the work.

\section{Disclosure}

Berger reports personal fees, nonfinancial support from Novartis, Boehringer Ingelheim, AstraZeneca, and GSK outside the submitted work; in addition, he has a patent EP N¹5152886.6, ie, new compositions and methods of treating and/or preventing COPD, which is pending. Laurent reports personal fees from Boehringer Ingelheim, Roche, Novartis, Bayer, Guerbet, and Chiesi outside the submitted work. Girodet reports personal fees and nonfinancial support from Novartis, Chiesi, Takeda, Boehringer Ingelheim, and AstraZeneca outside the submitted work. The other authors report no conflicts of interest in this work.

\section{References}

1. Galiè N, Humbert M, Vachiery JL, et al. 2015 ESC/ERS guidelines for the diagnosis and treatment of pulmonary hypertension: the joint Task Force for the diagnosis and treatment of pulmonary hypertension of the European Society of cardiology (ESC) and the European Respiratory Society (ERS): endorsed by: association for European paediatric and congenital cardiology (AEPC), International Society for Heart and lung transplantation (ISHLT). Eur Respir J. 2015;46(4):903-975.

2. Guignabert $\mathrm{C}, \mathrm{Tu} \mathrm{L}, \mathrm{Le}$ Hiress M, et al. Pathogenesis of pulmonary arterial hypertension: lessons from cancer. Eur Respir Rev. 2013;22(130): 543-551.

3. Cooper R, Ghali J, Simmons BE, Castaner A. Elevated pulmonary artery pressure. An independent predictor of mortality. Chest. 1991;99(1): 112-120.

4. Barst RJ, Rubin LJ, Long WA, et al. A comparison of continuous intravenous epoprostenol (prostacyclin) with conventional therapy for primary pulmonary hypertension. NEngl J Med. 1996;334(5):296-301.

5. Seeger W, Adir Y, Barberà JA, et al. Pulmonary hypertension in chronic lung diseases. J Am Coll Cardiol. 2013;62(25 Supp1):D109-D116.

6. Coste F, Dournes G, Dromer C, et al. CT evaluation of small pulmonary vessels area in patients with COPD with severe pulmonary hypertension. Thorax. 2016;71(9):830-837.

7. Miller MR, Hankinson J, Brusasco V, et al. Standardisation of spirometry. Eur Respir J. 2005;26(2):319-338.

8. Wanger J, Clausen JL, Coates A, et al. Standardisation of the measurement of lung volumes. Eur Respir J. 2005;26(3):511-522.

9. Montaudon M, Lederlin M, Reich S, et al. Bronchial measurements in patients with asthma: comparison of quantitative thin-section CT findings with those in healthy subjects and correlation with pathologic findings. Radiology. 2009;253(3):844-853.

10. Berger P, Perot V, Desbarats P, Tunon-de-Lara JM, Marthan R, Laurent F. Airway wall thickness in cigarette smokers: quantitative thin-section CT assessment. Radiology. 2005;235(3):1055-1064.

11. Dournes G, Laurent F, Coste F, et al. Computed tomographic measurement of airway remodeling and emphysema in advanced chronic obstructive pulmonary disease. Correlation with pulmonary hypertension. Am J Respir Crit Care Med. 2015;191(1):63-70.

12. Hoey ET, Mirsadraee S, Pepke-Zaba J, Jenkins DP, Gopalan D, Screaton NJ. Dual-energy CT angiography for assessment of regional pulmonary perfusion in patients with chronic thromboembolic pulmonary hypertension: initial experience. AJR Am J Roentgenol. 2011;196(3):524-532.

13. Montaudon M, Berger P, de Dietrich G, et al. Assessment of airways with three-dimensional quantitative thin-section CT: in vitro and in vivo validation. Radiology. 2007;242(2):563-572.

14. Matsuoka S, Washko GR, Yamashiro T, et al. Pulmonary hypertension and computed tomography measurement of small pulmonary vessels in severe emphysema. Am J Respir Crit Care Med. 2010;181(3):218-225.

15. Matsuoka S, Washko GR, Dransfield MT, et al. Quantitative CT measurement of cross-sectional area of small pulmonary vessel in COPD: correlations with emphysema and airflow limitation. Acad Radiol. 2010;17(1):93-99.

16. Uejima I, Matsuoka S, Yamashiro T, Yagihashi K, Kurihara Y, Nakajima Y. Quantitative computed tomographic measurement of a cross-sectional area of a small pulmonary vessel in nonsmokers without airflow limitation. Jpn J Radiol. 2011;29(4):251-255.

17. Wang Z, Chen X, Liu K, et al. Small pulmonary vascular alteration and acute exacerbations of COPD: quantitative computed tomography analysis. Int J Chron Obstruct Pulmon Dis. 2016;11:1965-1971.

18. Yoshimura K, Suzuki Y, Uto T, Sato J, Imokawa S, Suda T. Morphological changes in small pulmonary vessels are associated with severe acute exacerbation in chronic obstructive pulmonary disease. Int $J$ Chron Obstruct Pulmon Dis. 2016;11:1435-1445.

19. Barst RJ, McGoon M, Torbicki A, et al. Diagnosis and differential assessment of pulmonary arterial hypertension. $J$ Am Coll Cardiol. 2004;43(12 Suppl S):S40-S47.

20. Strange G, Playford D, Stewart S, et al. Pulmonary hypertension: prevalence and mortality in the Armadale echocardiography cohort. Heart. 2012;98(24):1805-1811. 
21. Fisher MR, Forfia PR, Chamera E, et al. Accuracy of Doppler echocardiography in the hemodynamic assessment of pulmonary hypertension. Am J Respir Crit Care Med. 2009;179(7):615-621.

22. Mooi W, Wagenvoort CA. Decreased numbers of pulmonary blood vessels: reality or artifact? J Pathol. 1983;141(4):441-447.

23. Chaouat A, Bugnet AS, Kadaoui N, et al. Severe pulmonary hypertension and chronic obstructive pulmonary disease. Am J Respir Crit Care Med. 2005;172(2):189-194.

24. Barberà JA, Peinado VI, Santos S. Pulmonary hypertension in chronic obstructive pulmonary disease. Eur Respir J. 2003;21(5):892-905.

25. Rahaghi FN, Ross JC, Agarwal M, et al. Pulmonary vascular morphology as an imaging biomarker in chronic thromboembolic pulmonary hypertension. Pulm Circ. 2016;6(1):70-81.
26. Burke CM, Glanville AR, Morris AJ, et al. Pulmonary function in advanced pulmonary hypertension. Thorax. 1987;42(2):131-135.

27. Meyer FJ, Ewert R, Hoeper MM, et al. Peripheral airway obstruction in primary pulmonary hypertension. Thorax. 2002;57(6):473-476.

28. Stenmark KR, Fagan KA, Frid MG. Hypoxia-induced pulmonary vascular remodeling: cellular and molecular mechanisms. Circ Res. 2006;99(7):675-691.

29. Kanemoto N, Sasamoto H. Pulmonary hemodynamics in primary pulmonary hypertension. Jpn Heart J. 1979;20(4):395-405.

30. Arcasoy SM, Christie JD, Ferrari VA, et al. Echocardiographic assessment of pulmonary hypertension in patients with advanced lung disease. Am J Respir Crit Care Med. 2003;167(5):735-740.

\section{Publish your work in this journal}

The International Journal of COPD is an international, peer-reviewed journal of therapeutics and pharmacology focusing on concise rapid reporting of clinical studies and reviews in COPD. Special focus is given to the pathophysiological processes underlying the disease, intervention programs, patient focused education, and self management protocols.

\section{Dovepress}

This journal is indexed on PubMed Central, MedLine and CAS. The manuscript management system is completely online and includes a very quick and fair peer-review system, which is all easy to use. Visit http://www.dovepress.com/testimonials.php to read real quotes from published authors.

Submit your manuscript here: http://www.dovepress.com/international-journal-of-chronic-obstructive-pulmonary-disease-journal 